\title{
Erratum to: Carbon Inputs from Miscanthus Displace Older Soil Organic Carbon Without Inducing Priming
}

\author{
Andy D. Robertson 1,2,3,5 - Christian A. Davies ${ }^{2} \cdot$ Pete Smith $^{3} \cdot$ Andy W. Stott ${ }^{4}$. \\ Emily L. Clark ${ }^{1,3} \cdot$ Niall P. McNamara ${ }^{1}$
}

Published online: 27 August 2016

(C) Springer Science+Business Media New York 2016

Erratum to: Bioenerg. Res.

DOI 10.1007/s12155-016-9772-9

Due to an error in communication between the authors and the publishers the title was not correct and merged with the next line of the manuscript. The title should simply read "Carbon inputs from Miscanthus displace older soil organic carbon without inducing priming". The original version has been corrected.

The online version of the original article can be found at http://dx.doi. org/10.1007/s12155-016-9772-9.

\footnotetext{
Andy D. Robertson

Andy.Robertson@ colostate.edu

1 Centre for Ecology \& Hydrology, Lancaster Environment Centre, Library Avenue, Bailrigg, Lancaster LA1 4AP, UK

2 Shell International Exploration and Production, Shell Technology Center Houston, 3333 Highway 6 South, Houston, TX 77082-3101, USA

3 Institute of Biological and Environmental Sciences, University of Aberdeen, 23 St Machar Drive, Aberdeen, Scotland AB24 3UU, UK

4 Life Sciences Mass Spectrometry Facility, Centre for Ecology \& Hydrology, Lancaster LA1 4AP, UK

5 Department of Soil and Crop Sciences, Colorado State University, Fort Collins, CO 80523, USA
} 